\title{
Analysis of the Correlation between Regional Economy and the Development of Logistics Industry

\author{
-Taking Gansu Province for Example
}

\author{
Ting He*, Hanping Hou \\ School of Economics and Management \\ Beijing Jiaotong University \\ Beijing, China \\ 2649362226@qq.com
}

Shaoqing Geng, Chenyang Zhao

School of Economics and Management

Beijing Jiaotong University

Beijing, China

17125513@bjtu.edu.cn

\author{
Jianliang Yang \\ School of Economics and Management \\ Beijing University of Chemical Technology \\ Beijing, China \\ yangjianliang6265@126.com
}

\author{
Wenjuan Wang \\ Assistant Engineer \\ Space star technology co., LTD \\ Beijing, China \\ Lixueb2141@163.com
}

\begin{abstract}
As one of the important provinces on the "One Belt And One Road", Gansu province has received more and more attention from the society. At the same time, the harmony and interaction between the development of its logistics industry and the development of regional economy also rouse wide social attention. Considering the availability of data and the development of logistics industry in Gansu province, the article will use economic indicators and related logistics index in Statistical Bulletin of National Economic and Social Development of 2005-2017 and the Statistical Yearbook of 2005-2017 issued by statistical bureau of Gansu province. The analysis shows that there have been obvious uncoordinated problems between the development of regional economy and logistics industry in Gansu province in recent years. According to these problems, the article analyzes the cause of uncoordinated development and proposes some corresponding measures with a consideration of provincial reality.
\end{abstract}

Keywords-regional economy; logistics industry; analysis of the correlation; One Belt And One Road

\section{INTRODUCTION}

Under the background of the "One Belt And One Road", Gansu Province, as an important part of the Silk Road Economic Belt, is particularly important in its economic development with its unique location advantages, especially its economic and logistics industries. To a certain extent, the issue of coordinated development will have a major impact on the development of the entire Silk Road Economic Belt. This paper will deeply study the development of regional economy and logistics industry in Gansu Province. By collecting relevant economic data and scientifically analyzing it, this paper will further explore the correlation between the two, and discover the problems between the development of regional economy and logistics industry in Gansu Province, and propose corresponding solutions from the scientific point of view. To a certain extent, it provides a valuable reference for policy makers, thus contributing to the sound and rapid development of Gansu Province's economy.

Overseas researches on the development of regional economy and logistics industry pay more attention to the coordination of the two, using a combination of qualitative and quantitative methods. For example, Lan (2016) [1] used Bayesian network to analyze the key factors of coordinated development of urban economy and logistics, and put forward relevant logistics development suggestions. Some scholars also qualitatively evaluate the relationship between the two. For example, Maciulis .etc.(2009) [2] qualitatively analyzed the positive and negative impacts of transportation on the economy, and evaluated the feasibility of sustainable transportation systems. Some scholars in China use qualitative methods when studying the development of regional economy and logistics industry (Hui Zhao, 2015 [3]). Some scholars use quantitative methods to study the development of regional economy and logistics industry, the actual supply indicators such as freight turnover and cargo throughput are used to measure the development of logistics industry, and further establish a regression model to analyze the development of regional economy and logistics industry. (Jun Xia, 2015 [4]). Meiqing Zhang et al. (2012) [5] study the coordinated development of logistics industry and regional economy, the related research was carried out on the basis of symbiosis theory, and on this basis, the coordinated development of regional economy and logistics industry was put forward.

The article collects relevant economic data and logistics industry development data from 2005 to 2017 in Gansu Province to quantitatively analyze the development status of regional economy and logistics industry in Gansu Province. By consulting relevant literature, this paper will use the three 
indicators of transportation line length, transportation, warehousing and postal industry added value, as well as transportation, warehousing and postal investment, from logistics industry infrastructure, logistics industry market structure and logistics industry. The three aspects of fixed assets investment measure the development level of logistics industry. Through the use of SPSS software to analyze the development of regional economy and logistics industry in Gansu Province, understand the current situation of the coordinated development of regional economy and logistics industry in Gansu Province, and further propose corresponding development measures.

\section{EMPIRICAL ANALYSIS}

\section{A. Selection of Indicators and Data Processing}

In terms of the selection of indicators, this paper will select GDP as an economic indicator to measure the level of regional economic development in Gansu Province. When selecting logistics indicators, this paper will use the total supply indicators of the logistics industry to measure the development of the logistics industry in Gansu Province. Through the study of a large number of related literatures, this paper will measure the total supply level of logistics industry in Gansu Province through three aspects: logistics industry infrastructure, logistics industry market structure and logistics industry fixed asset investment. The specific aspects will select transportation line length and traffic. The three indicators of transportation, warehousing and postal industry added value, as well as transportation, warehousing and postal investment, specifically indicate the development of the logistics industry in Gansu Province. Among them, in the logistics industry infrastructure, because of the northwest inland location of Gansu Province, its transportation mainly depends on railways and highways, while the development of aviation, water transport and pipeline is relatively slow, this paper mainly uses mileage of railway production and operation miles of road production published in the Gansu Provincial Statistical Yearbook in terms of transport line length. At the same time, in order to obtain the availability and simplicity of data, this paper does not weight the operating mileage of railway production and the operating mileage of highway production. As the logistics industry as an emerging industry, the statistics of many data are still incomplete. Through the study of a large number of documents, this paper will learn the practice of most scholars, using the added value of transportation, warehousing and postal industry to represent the added value of the logistics industry as the market structure of the logistics industry. Indicators measure the total supply level of the logistics industry. In addition, the development of the logistics industry is inseparable from the logistics industry's investment in fixed assets, and the annual investment in transportation, warehousing and postal industry will directly increase the total supply level of the logistics industry to a certain extent. This article will use transportation and warehousing. And the investment in the postal industry represents the fixed assets investment in the logistics industry to study the development of regional economy and logistics industry in Gansu Province.
In terms of data processing, in order to eliminate the impact of price on GDP, transportation, warehousing and postal industry added value, as well as transportation, warehousing and postal investment, and the consistency of data processing path, this paper does not use GDP revision index when correcting GDP. Instead, using the CPI index to correct the investment in transportation, warehousing and postal services, and the added value of transportation, warehousing and postal services, the CPI index is used to correct GDP. At the same time, for the authoritative reliability and availability of data, this paper selects the fixed-base index issued by the National Bureau of Statistics based on 1978 as the base year when selecting the CPI index. In the segmentation processing of data, due to the use of the CPI index to correct the actual GDP of Gansu Province in 20052017, the actual investment in transportation, warehousing and postal services, the actual added value of transportation, warehousing and postal services, and the length of transport routes The broken line chart shows that the data in 2013 and beyond have changed significantly compared to 2005-2012. Based on this, in order to demonstrate the rigor of the analysis, this paper will specifically segment the 2005-2017 data into 2005-2012 data and 2013-2017 data and will explore the reasons for the large changes in the data.

\section{B. Analysis of the Correlation}

The GDP, transportation, warehousing and storage of Gansu Province in 2005-2017 were obtained by reviewing the relevant statistical data of the Gansu Provincial National Economic and Social Development Statistics Bulletin and the 2005-2017 Gansu Statistical Yearbook published by the Gansu Provincial Bureau of Statistics. Postal investment, transportation, warehousing and postal industry added value and transport line length data. Use the 2005-2017 Consumer Price Index $(1978=100)$ published on the website of the National Bureau of Statistics of the People's Republic of China, utilize the CPI index for 2005-2017 Gansu Province's GDP, transportation, warehousing and postal investment, transportation, warehousing and after the value-added of the postal industry was revised, the actual GDP, the actual investment amount of transportation, warehousing and postal services, the actual added value of transportation, warehousing and postal services and the length of transport routes were obtained in 2005-2017 of Gansu Province (Table I).

TABLE I. ST ATIST ICSOF THE ACTUAL GDP, THE ACT UAL INVEST MENT, THE ACT UAL ADDED VALUE AND THE LENGT H OF TRANSPORT ROUTES IN 20052017 OF GANSU PROVINCE(UNIT: ONE HUNDRED MILLION RMB)

\begin{tabular}{ccccc}
\hline Year & $\begin{array}{c}\text { The actual } \\
\text { GDP }\end{array}$ & $\begin{array}{c}\text { The actual } \\
\text { investment }\end{array}$ & $\begin{array}{c}\text { The actual } \\
\text { added value }\end{array}$ & $\begin{array}{c}\text { The length of } \\
\text { transport routes }\end{array}$ \\
\hline 2005 & 415.55 & 28.27 & 41.13 & 43343.00 \\
2006 & 483.01 & 28.81 & 36.00 & 97629.00 \\
2007 & 546.84 & 23.27 & 37.32 & 102760.00 \\
2008 & 607.64 & 20.24 & 40.39 & 107787.00 \\
2009 & 651.71 & 27.95 & 41.16 & 116149.00 \\
2010 & 768.41 & 34.95 & 42.38 & 121028.00 \\
2011 & 888.50 & 40.34 & 45.89 & 125845.00 \\
\hline
\end{tabular}




\begin{tabular}{lcccc}
\hline \multicolumn{5}{c}{ Cont. to TABLE I } \\
\hline 2012 & 974.68 & 53.16 & 55.14 & 133395.00 \\
2013 & 1053.80 & 65.51 & 58.37 & 135883.00 \\
2014 & 1126.63 & 129.80 & 46.27 & 141050.00 \\
2015 & 1103.76 & 132.46 & 44.64 & 143324.00 \\
2016 & 1139.77 & 175.31 & 43.27 & 145653.00 \\
2017 & 1205.37 & 150.20 & 46.08 & 146207.00 \\
\hline
\end{tabular}

National Bureau of Statistics of People's Republic of China: http://www.stats.gov.cn/.

b. Statistical Bulletin of National Economic and Social Development of 2005-2017. c. The Statistical Yearbook of 2005-2017.

The data in Table 1 is entered into SPSS19.0 software, and the actual GDP and the fixed investment of logistics industry, namely the actual investment amount of transportation, warehousing and postal industry, and logistics industry, are obtained from 2005-2012 and 2013-2017 respectively of Gansu Province. The market structure is the Pearson correlation coefficient of the actual added value of transportation, warehousing and postal industry, and the logistics industry infrastructure, and the length of the transportation line, as shown in Table II.

TABLE II. THE PEARSON CORRELATION COEFFICIENT (UNIT: ONE HUNDRED MILLION RMB)

\begin{tabular}{cccc}
\hline $\begin{array}{c}\text { The actual } \\
\text { GDP }\end{array}$ & $\begin{array}{c}\text { The actual } \\
\text { investment }\end{array}$ & $\begin{array}{c}\text { The actual added } \\
\text { value }\end{array}$ & $\begin{array}{c}\text { The length of } \\
\text { transport routes }\end{array}$ \\
\hline $2005-2012$ & $0.827^{*}(0.011)$ & $0.848^{* *}(0.008)$ & $0.827^{*}(0.011)$ \\
$2013-2017$ & $0.760(0.136)$ & $-0.666(0.220)$ & $0.860(0.061)$ \\
\hline
\end{tabular}

It can be seen from Table 2 that in 2005-2012, the actual GDP of Gansu Province was significantly correlated with the actual investment amount, the actual value added and the length of the transportation line, and the correlation coefficient was greater than 0.5 and both were higher than 0.8 , indicating Gansu Province. The development of regional economy is highly correlated with the development of logistics industry in Gansu Province, and the development of regional economy and logistics industry in Gansu Province is more coordinated during this period. However, according to the data of 20132017 in the correlation coefficient table, it can be seen that the $\mathrm{P}$ value of the correlation coefficient between the regional economy of Gansu Province and the various logistics indicators for measuring the development of the logistics industry is greater than 0.05 , that is, they are not significantly correlated, and the actual The correlation coefficient between GDP and the market structure of the logistics industry, namely the actual added value of transportation, warehousing and postal industry, is negative. Based on this, it can be seen that since 2013, the regional economy of Gansu Province and the logistics industry in Gansu Province have developed inconsistent. In this regard, this paper will analyze the development of regional economy and logistics industry in Gansu Province in recent years, and analyze the causes of uncoordinated development, and propose corresponding countermeasures.

\section{Empirical Conclusion and Analysis}

According to the relevant theories of macroeconomics, the development of regional economy and logistics industry should be relevant. However, according to the above correlation coefficient analysis, Gansu Province has shown the problem of uncoordinated development of regional economic development and logistics industry in the development of logistics industry in recent years, and even the actual added value of transportation, warehousing and postal industry. The actual GDP shows a reverse development. This phenomenon will not be conducive to the sound development of the logistics industry in Gansu Province, and will even hinder the stable and healthy development of Gansu Province's regional economy to a certain extent. Therefore, it is particularly important to explore the causes of the uncoordinated development of regional economy and logistics industry in Gansu Province and propose corresponding solutions.

For the uncoordinated development of regional economic and logistics industry development in Gansu Province, the following reasons are summarized by studying the current situation of regional economic and logistics industry development in Gansu Province in recent years:

- The economic development is stable and the logistics industry is developing rapidly.

- The development of logistics industry in Gansu Province is rapid, and the effective use of funds is not high.

- Gansu Province's logistics industry is developing at a fast pace and unbalanced development.

- The access mechanism of logistics industry in Gansu Province is still not perfect, and the main development of logistics industry is uneven.

\section{SUGGESTIONS}

In view of the uncoordinated development of regional economy and logistics industry in Gansu Province based on the correlation coefficient, combined with the abovementioned reasons, the countermeasures for the coordinated development of regional economy and logistics industry in Gansu Province are as follows:

1) Improve the rules and regulations for the development of the logistics industry and create an enabling environment for the development of the logistics industry in Gansu Province

The development of logistics industry in Gansu Province cannot be separated from the support of relevant rules and regulations. It is necessary to improve the logistics industry access and exit mechanism, improve the low entry status of the logistics industry, implement the last elimination system, and maintain the logistics industry market in Gansu Province. Develop order, improve the logistics industry to develop the market, and gradually improve the overall quality of the logistics industry development. 
2) Play a policy-oriented role and comprehensively develop the logistics industry

The Gansu provincial government should adopt relevant policies to promote the development of logistics industry in Gansu Province, especially for the slow and weak development of the logistics industry in Gansu Province, and consciously guide social capital to develop the logistics industry in Gansu Province in a comprehensive and balanced manner. Especially for the infrastructure construction in the development of logistics industry in Gansu Province, it is necessary to strengthen the policy inclination and encourage the capital to develop the logistics infrastructure of Gansu Province.

3) Give play to the government's regulatory role and promote the development of relevant policies for the development of the logistics industry

In recent years, a series of policies to support the development of the logistics industry have been introduced one after another, but in the landing stage of these policy measures, the expected effects of policy implementation have not been achieved, and the development of the regional economy and the logistics industry still has inconsistencies. Therefore, the government and all sectors of society should strengthen supervision and mutual supervision in the implementation stage of relevant policies supporting the development of the logistics industry, and jointly promote the implementation of relevant policies, in order to realize the positive effects of relevant policies and measures to support the development of the logistics industry, and promote the logistics industry in Gansu Province.

4) Integrate logistics industry development resources and comprehensively improve the development level of logistics industry

The development of logistics industry in Gansu Province should integrate the development resources of logistics industry in Gansu Province, strengthen the utilization of advanced logistics information technology and logistics information system, increase the introduction of relevant concepts and technologies for the development of the international and domestic logistics industry, and strengthen the development capacity of the Gansu province's logistics industry. At the same time, the Gansu provincial government should encourage and guide all sectors of society to actively promote the transformation and upgrading of the logistics industry in Gansu Province, and strive to create an efficient and intelligent logistics system to inject new vitality into the coordinated development of the regional economy and logistics industry in Gansu Province.

5) Introduce logistics professionals to improve the quality of logistics industry development

Gansu Province should establish a long-term and effective mechanism to attract and encourage logistics professionals to contribute to the development of logistics industry in Gansu Province, and attract senior talents who lead the development of logistics industry in Gansu Province to contribute to the coordinated development of Gansu Province's regional economy and logistics industry. At the same time, Gansu Province should strengthen the training of logistics management professionals, implement the linkage mechanism of production, education and research, encourage and support the introduction of high-end logistics talents, and reserve talents for the development of logistics industry in Gansu Province.

6) Increase the openness of the development of logistics industry in Gansu Province and encourage the diversified capital to enter the logistics industry

The Gansu provincial government should introduce relevant rules and regulations to encourage diversified capital to enter the logistics industry of Gansu Province, and strive to improve the diversification of the main body of logistics industry development in Gansu Province. The diversification of the main body of the logistics industry can not only provide new ideas and new methods for the development of the logistics industry in Gansu Province, but also help to further improve the openness and tolerance of the logistics industry in Gansu Province, and thus better absorb the international and domestic advanced logistics. Technology and management concepts promote the diversified and healthy development of the logistics industry in Gansu Province.

\section{CONCLUSION}

Under the guidance of the Belt and Road Initiative, to solve the problem of coordinated development of the regional economy and logistics industry in Gansu Province, we must simultaneously play the role of the government and the main body of the logistics industry, and work together to realize the coordinated green development of the regional economy and logistics industry in Gansu Province. When developing the logistics industry, Gansu Province should strengthen the logistics, capital, technology, talents and other reserves through the relevant policy guidance, and create a good development environment for the logistics industry in Gansu Province. At the same time, Gansu Province should vigorously enhance the attraction and cohesiveness of the logistics industry through relevant policy systems, fully mobilize resources from all walks of life, focus on coordinating the development relationship between Gansu Province's regional economy and logistics industry, and inject new resources into the development of Gansu Province's regional economy and logistics industry.

\section{REFERENCES}

[1] Lan,S.L. Zhong, Ray Y. Coordinated Development between Metropolitan Economy and Logistics for Sustainability[J]. Resources, Conservation and Recycling,2016,(128): 345-354.

[2] MACIULIS A, VASILIAUSKAS A V, JAKUBAU SKAS G. The Impact of Transport on the Competitiveness of National Economy[J].Transport, 2009,24(2): 93-99.

[3] Hui Zhao. Research on Coordinated Development of Regional Economy and Logistics Industry [J]. Journal of Harbin Vocational \&Technical College, 2015,(1):92-93. In Chinese

[4] Jun Xia. Study on Development of Logistics Industry and Regional Economy under Supply Chain Mode[J]. Logistics Technology, 2015, 34:172-174. In Chinese

[5] Meiqing Zhang, Ye Zhou, Changlong Zhou. A Study on Coordinated Development of Logistics Industry and Regional Economy Based on Symbiotic Theory[J]. Journal of Beijing Jiaotong University(Social Sciences Edition), 2012, 11(1):27-34. In Chinese 